\title{
COMPARING THE METHODS OF A3 AND CANVAS
}

\author{
Lauri Koskela ${ }^{1}$, Rafaella D. Broft ${ }^{2}$, Ergo Pikas $^{3}$, and Algan Tezel ${ }^{4}$
}

\begin{abstract}
The method of A3, which originated in the framework of the Toyota Production System, is used for collaborative problem solving, status reporting, and presenting proposals. It is now widely used as a part of the implementation of lean in different industries. In turn, the Canvas method was initially developed, through academic research, for generating business models, but over time it has been generalised for many other situations. In subsequent research, design principles for Canvases have been developed. The use of the Canvas method has rapidly increased in practice.

As these two methods seem to have similarities regarding application areas and working principles, it is of interest to compare them. The following questions are addressed: How are these two methods similar and dissimilar? Are there underlying theories that could shed new light on both methods? A better understanding of these methods, both theoretically and practically, might be beneficial for their use in different contexts and scenarios. Especially, enhanced mastery of these methods would be instrumental for collaborative resolution of the well-known problems in construction.
\end{abstract}

\section{KEYWORDS}

Lean construction, A3 method, Canvas method, visual management, theory.

\section{INTRODUCTION}

Since the influential reports on business education in the United States (Gordon \& Howell 1959; Pierson 1959), the focus in management science has been on decision making, and subsequently, a significant number of methods, models and tools have been developed to support it. Other mental operations in management, such as problem solving and designing, have received remarkably little attention. However, around ten years ago, two methods for problem-solving and designing solutions, A3 and Canvas, emerged in the English language literature, and both have diffused rapidly. Neither came from mainstream management research: A3 has organically evolved as part of Toyota Production System (Sobek II \& Smalley 2008), and Canvas was consolidated in a (partially) crowd-sourced business book (Osterwalder \& Pigneur 2010), whilst also based on a doctoral dissertation in information systems (Osterwalder 2004).

1 Professor, School of Art, Design and Architecture, University of Huddersfield, UK, 1.koskela@hud.ac.uk, ORCID 0000-0003-4449-2281

2 PhD Candidate (part-time), The Bartlett School of Construction \& Project Management, University College London, UK, r.d.broft@gmail.com, ORDCID 0000-0002-3724-854X | Expert in (Lean) SCM.

3 Postdoc, School of Engineering, Department of Civil Engineering, Aalto University, Finland, ergo.pikas@aalto.fi, ORCID 0000-0001-5691-685X

4 Senior Lecturer, Department of Architecture and 3D Design, University of Huddersfield, UK, a.tezel@hud.ac.uk, ORCID 0000-0003-3903-6126 
The method of A3 is mainly used for collaborative problem solving, status reporting and presenting proposals. It is currently widely applied as part of the implementation of lean in different industries (Mann 2017). Canvas was initially meant for designing business models, but since its development, it has been generalised for many other situations, such as project planning and the planning of academic papers. These two methods seem to have many similarities. Both support collaborative working and rely on visual structuring of processes or their outcomes. Their application areas are to some extent overlapping (problem solving involves designing the solution, and in turn, designing often starts from a problem).

Recently, the underlying philosophical assumptions of lean, falling into ontology and epistemology, have been pinpointed (Koskela 2020). Lean arguably subscribes to process ontology (metaphysics), especially addressing the change of the phenomenon of interest, as well as the connections of that phenomenon to other phenomena. In lean practice, change is reflected in the emphasis on continuous improvement, whereas connections are tackled through collaboration. Epistemologically, lean is best described through Plan-DoCheck-Act, a cycle from the existing situation to the comprehension of the problem and the conception of a solution and back to reality for testing and validation. The practical method of A3 completely coheres with these philosophical starting points of lean. The method of Canvas has its origin outside lean, and thus a comparison between them might shed light on aspects that cannot be discerned when they are considered as such, in isolation. This might support widening of the lean theory.

Thus, the purpose of this paper is to compare the methods of A3 and Canvas. The following questions are addressed: How are these two methods similar and dissimilar? Are there underlying theories that could shed new light on both methods? How could the slightly different foci in their application cases be illustrated in a given context? Can a better understanding of these methods benefit their use in different context and scenarios?

The paper is structured as follows. First, there is a description of the emergence, key features and application experience regarding the A3 method. Second, a corresponding account is given for the Canvas method, followed by a short description of the evolution of both approaches. A comparison is set out next. Then, their underlying concepts are discussed and clarified, followed by an illustration of their distinct application in construction. The paper is completed with conclusions.

\section{TWO METHODS}

\section{Origins ANd Key Features of the A3 Method}

In the lean literature, the A3 refers, as the name suggests, to a single sheet of ISO A3-size paper $(297 \mathrm{~mm} \times 420 \mathrm{~mm})$ that is used to structure, summarise and document a thinking process (Shook 2008; Sobek II and Smalley 2008). This thinking process is generally based on Shewhart's (1931) Plan-Do-Check-Act (PDCA) cycle for problem solving and continuous improvement.

The A3 process emerged at Toyota as part of the Toyota Production System (TPS) in the 1960s to summarise kaizen circle activities (Dennis 2007). Like many systems in the TPS, it seems to have evolved organically and incrementally in practice as a countermeasure to challenges rather than based on theoretical knowledge (Fujimoto 1999). Therefore, it is impossible to pinpoint the inventors of the $A 3$. The main challenge faced by Toyota that eventually led to the A3 was to effectively capture all aspects of a complex thinking process on a single communication medium. The preference was for a 
standardised, visual and succinct manner to reduce the time spent on inefficient conventional report writing, reading, and archiving activities, and to streamline the reporting process (Chakravorty, 2009). The A3 process caught the attention of Western observers of the TPS at the end of the 1990s, and after almost a decade, a series of books in English were published on A3s (Shook 2008; Sobek II and Smalley 2008). Applications in healthcare (Jackson 2007) were prominent during the initial diffusion of the A3 outside Japan, followed by activities in construction (Parrish et al. 2009) and product development (Raudberget and Bjursell 2014)

A3s typically contain nine sections that are progressively developed with objective, clear, visual (graphical) and relevant data to report on and to think through an initiative, issue, project or a strategy (Jackson 2006; Dennis 2007; Sobek II and Smalley 2008). These sections are stated below (and shown in Figure 1):

1) Theme (Background): stating the problem, issue or challenge, located at the top;

2) Problem statement (Current condition): defining the motive, context and importance of the project in its current state - often through a value stream map or process diagram;

3) Target statement: defining the scope of the project in its future state with desired outcomes and the targeted level performance;

4) Systematic/scientific analysis: finding the root causes through the ' 5 Whys', a cost-benefit analysis, a cause-and-effect diagram, the design of an experiment, etc.;

5) A possible solution: proposing a solution, often involving cross-functional coordination;

6) Implementation timeline for the proposed solution including actions, the responsible persons and due dates;

7) Impact: presenting the achieved results through a before/after analysis;

8) Follow-up: showing the actions still required by whom and when with learning points to share;

9) Date and the name of the individual or group owning or responsible.

\begin{tabular}{|l|l|}
\hline Step 1: Background & Step 5: Proposed countermeasures \\
\hline Step 2: Current conditions & Step 6: Plan \\
\hline Step 3: Targets & Step 7: Impact \\
\hline Step 4: Analysis & Step 8: Follow-up \\
\hline
\end{tabular}

Figure 1: A schematic problem-solving A3 template

\section{Origins And Key Features of the Canvas Method}

In business, management and information systems research, the development of visual methods and tools to support and manage processes of solving (ill-structured) problems (Simon 1977), by teams of diverse individuals, have become a relevant research field (Avdiji et al. 2018; Trimi and Berbegal-Mirabent 2012). This research stream builds on ideas of design science research (Gregor and Hevner 2013; Hevner and Chatterjee 2010) 
and co-design (Sanders and Stappers 2008), which otherwise have evolved in separate domains (Avdiji et al. 2018).

The Business Model Canvas (BMC) is considered the most popular product of this research stream (Avdiji et al. 2018) - a tool that is intended to facilitate the discussion on and the generation of innovative business models (Osterwalder and Pigneur 2010). The visual representation of different business model elements and their relationships is expected to guide the collaboration between stakeholders in the early stages of prototyping and feedback gathering, including any revisions (iterations) (Trimi and Berbegal-Mirabent 2012).

The motivation to develop the BMC is best illustrated by the words of Osterwalder and Pigneur themselves (2010, p.15): "The starting point for any good discussion, meeting, or workshop on business model innovation should be a shared understanding of what a business model actually is. [...] The challenge is that the concept must be simple, relevant, and intuitively understandable, while not oversimplifying the complexities of how enterprises function." The authors had two goals in mind for developing the BMC (Osterwalder and Pigneur 2012): (1) it should aid stakeholders in understanding a business model, and (2) it should improve the communication based on shared understanding.

The work to develop a BMC began with the paper published in the early $2000 \mathrm{~s}$ (Osterwalder and Pigneur 2002) and was followed by Osterwalder's (2004) thesis. Osterwalder and Pigneur studied the possibilities to describe and represent business models by following the ontology building methodology proposed by Uschold and King (1995). As an outcome, a conceptual model named the Business Model Ontology (BMO) was developed, specifying the main elements of business models and their relationships.

The BMC specifies nine elements and the relationships between the elements through a visual composition of a template, as shown in Figure 2 (Osterwalder and Pigneur 2010). The visual template is organised and composed in a way to support the intuitive recognition of relationships between the elements (Maurya 2010). Principally, the elements are laid around the middle of a template with the value proposition at the centre (Avdiji et al. 2018). To the left are business model elements related to activities, resources, partners and costs, whereas to the right are customer relationships, channels, customer segments and revenues.

Since then, BMC has influenced research as well as practice - in the latter case, according to some scholars, the BMC has become the standard for developing and describing business models (Jones and Gregor 2006). It is seen as an important tool (Trimi and Berbegal-Mirabent 2012), or arguably the most important tool (John and Kundisch 2015), for entrepreneurs to continuously reflect and develop business models.

\begin{tabular}{|c|c|c|c|c|}
\hline \multirow{2}{*}{ Key Partners } & Key Activities & \multirow{2}{*}{$\begin{array}{l}\text { Value } \\
\text { Proposition }\end{array}$} & $\begin{array}{l}\text { Customer } \\
\text { Relationships }\end{array}$ & \multirow{2}{*}{$\begin{array}{l}\text { Customer } \\
\text { Segments }\end{array}$} \\
\hline & Key Resources & & Channels & \\
\hline \multicolumn{3}{|l|}{ Cost Structure } & \multicolumn{2}{|c|}{ Revenue Streams } \\
\hline
\end{tabular}

Figure 2: A schematic Business Model Canvas (BMC) template

(Osterwalder and Pigneur 2010) 


\section{EvOLUTION OF THE TWO METHODS}

The 'original' A3, as described above, is often referred to as the 'problem-solving A3'. Nowadays, the A3 is also used for (Jackson 2006; Dennis 2007; Sobek II and Smalley 2008; Richardson 2011):

- Reporting the project status (the 'status A3') - showing the progress of a longterm project with the original plan versus the actual status and its action items;

- Reporting work-related proposals (the 'proposal A3') - 'future state' oriented A3s, articulating where and how one wants to improve the situation within a department or area by suggesting an idea supporting some performance targets; and

- Reporting strategic planning (the 'strategy A3') - prepared by senior management and focusing on the company Hoshin (business plan) over a longer term with a gap analysis and action plans for the iterative catchball or nemawashi practice.

There are general conventions across all types of A3s apart from being on an A3-size paper (Shook 2008; Sobek II and Smalley 2008); (i) follow a general template, (ii) rely on figures, graphics, hard (objective) data and vital information, (iii) tell a "story" following a logical flow, and (iv) are working documents for team/group communication, collaboration, and memory. Populating an A3 is an iterative, progressive process (sometimes referred to as the 'A3 process'), that, as mentioned before, generally follows the PDCA-cycle.

The academic and practical success of the BMC has inspired a surge of related research (Trimi and Berbegal-Mirabent 2012). Since the publication and dissemination of BMC, many methods and tools for managing collaborative processes and solving illstructured problems have been developed. For example, to name a few, the 'Project Canvas' (Habermann and Schmidt 2014) and the 'Customer Journey Mapping Game' (Kalbach 2016) reuse the visualisation aspect of the BMC. These visual templates, in contrast to textual or verbal communication modes, benefit from their structure, offering "representational guidance" (Suthers 2001).

The observation of Canvases being developed in new settings has encouraged scholars to develop design principles for conceiving and producing Canvases. Avdiji et al. (2018) defined three principles, including (1) ontology development for problem framing, (2) visualisation for facilitating the creation of shared understanding, and (3) implementation in the co-design process. With these three principles ${ }^{5}$, the authors hope to facilitate practitioners and researchers in developing new tools that would assist a new way of managing and working, especially when there is a need for design in management (Avdiji et al. 2018).

\section{COMPARISON OF THE TWO METHODS}

In this Section, the two methods are compared, starting with an initial comparison of their key features, and followed by a theoretical explanation of the methods.

\section{COMPARISON BASED ON KEY FEATURES}

Table 1 presents a succinct comparison of the key features of the A3 and Canvas methods. While several characteristics are shared, there are also differing characteristics.

\footnotetext{
${ }^{5}$ This list of rules is open for critique. Its originators have not spotted the significance of the notions of fit, integrity, etc., in connection to Canvases.
} 
Table 1: Comparison of the key features of the A3 and Canvas methods

\begin{tabular}{|c|c|c|}
\hline & A3 & Canvas \\
\hline Similar characteristics & \multicolumn{2}{|c|}{$\begin{array}{l}\text { - A visual and succinct presentation, allowing an at a glance } \\
\text { observation; } \\
\text { - } \\
\text { About the creation of a shared understanding of a complex process } \\
\text { - } \quad \text { Documenting and describing the current state (how things are done); } \\
\text { - } \quad \text { Presenting a basis for future targets (how things could be improved); } \\
\text { - } \quad \text { Facilitating the documentation and diffusion of outputs; } \\
\text { - } \quad \text { Providing collaborative document development to a group; } \\
\text { - } \quad \text { Facilitating a structured group discussion and decision making; } \\
\text { - } \quad \text { Following a predefined, standard template consisting of building } \\
\text { - } \quad \text { Plocks; } \\
\text { - } \quad \text { Serving as a reference to group/organisational memory; } \\
\text { - } \quad \text { Focused on a subject, including its core dimensions; } \\
\text { - } \quad \text { Demonstrating how different parts of a process or system interrelate } \\
\text { - } \quad \text { Re each other; } \\
\end{array}$} \\
\hline \multirow[t]{5}{*}{ Differing characteristics } & $\begin{array}{l}\text { Describing a thinking process - } \\
\text { often a sequential problem- } \\
\text { solving process }\end{array}$ & $\begin{array}{l}\text { Describing a system with coherent } \\
\text { parts, a constellation, around a } \\
\text { value proposition - often for } \\
\text { mapping out a business with its key } \\
\text { driver parts }\end{array}$ \\
\hline & $\begin{array}{l}\text { Preference for a given size of the } \\
\text { document (the A3) }\end{array}$ & $\begin{array}{l}\text { Flexible regarding the size of the } \\
\text { document (a single sheet of paper) }\end{array}$ \\
\hline & Fact-based & Opinion or idea-based \\
\hline & $\begin{array}{l}\text { Often forcing groups to think } \\
\text { about the root-causes of issues } \\
\text { and best course action }\end{array}$ & $\begin{array}{l}\text { Often forcing groups to think about } \\
\text { the value provided to customers }\end{array}$ \\
\hline & $\begin{array}{l}\text { Executed iteratively as a project } \\
\text { with predefined start and end } \\
\text { dates, and current versus target } \\
\text { states (goals). When the target } \\
\text { state has been reached, it provides } \\
\text { the basis for a new current state } \\
\text { for another A3 project. }\end{array}$ & $\begin{array}{l}\text { Executed as a snapshot of a system, } \\
\text { leading to discussing, mapping, } \\
\text { designing and inventing new } \\
\text { systems. Canvas needs to be } \\
\text { evaluated continuously if the model } \\
\text { is to fit the environment, so the } \\
\text { individual building blocks need to } \\
\text { be reviewed and updated. They also } \\
\text { provide the basis for new system } \\
\text { propositions. }\end{array}$ \\
\hline
\end{tabular}

\section{THEORETICAL EXPLANATION}

There has been very limited work regarding the theoretical explanation of A3 and Canvas. As both arguably fall into the domain of visual management, explanations deriving from that area are applicable. Thus, both A3 and Canvas may be explained through (Koskela et al. 2018):

- Rapid and immediate access to information, supported by System 1 of cognition (Kahneman 2011);

- Spraction (Tversky 2015) - when thought overwhelms the mind, the mind puts it into the world;

- The promotion of the creation of common ground and shared understanding, necessary for both communication and collaboration (Koskela et al. 2016). 
On the other hand, as for their differing features, of course, the explanations differ too. Regarding A3, its underlying scheme is the PDCA-cycle (Shewhart 1931), which, in turn, can be interpreted as reflecting the Aristotelian epistemology (Koskela \& al. 2018). Further, the PDCA cycle arguably embraces the stages of analysis (i.e. reasoning backwards from problems to their causes) and synthesis (i.e. reasoning forward from elements of the solution to achieving the complete solution), and thus the ancient method of analysis (Koskela et al. 2014) lies at the base of the A3 method.

The underlying scheme of Canvas is arguably somewhat hidden, as the treatments of its originators give it a disproportionately minor role - it is just shortly mentioned. In his dissertation, Osterwalder (2004, p.21) states: "Designing a coherent business model where all the elements are mutually reinforcing or at least optimised is not an easy task." In turn, the seminal book (Osterwalder \& Pigneur 2010, p. 212) contains the following sentence: "Business model assessment, therefore, alternates between individual elements and overall integrity." Thus, the Business Model Canvas ${ }^{6}$ is based on the idea of fit or coherence between parts of a system (in this case, a business model). Although the idea of fit or integrity is used often, these concepts are not well supported by theoretical work (however, see the discussion on the idea of integrity by Clark and Fujimoto (1990)). Historically, prior treatments of fit, etc., can be found in the ancient discipline of rhetoric, where the composition of coherent communication was addressed (Chanal and Tannery 2009).

In general, the theoretical explanation of both A3 and Canvas is still shallow, inviting more research in this area.

\section{DISCUSSION}

\section{TENDENCIES TOWARDS EPISTEMOLOGICAL DILUTION}

When theoretically informed new methods are adapted to new situations, a phenomenon called epistemological dilution may occur. According to Papert (2000), epistemological dilution refers to a situation where, rather than the original big idea itself, certain implications of it diffuse. This happens when the finer but somewhat invisible theoretical ideas behind a method get lost, and just the more visible characteristics of the method get transmitted.

In the case of $\mathrm{A} 3$, the original types of $\mathrm{A} 3$ sheet follow the PDCA-cycle (except for the 'status A3', covering only the two last parts of the PDCA cycle (Sobek II and Smalley 2008)). However, a recent article on the use of A3's for proposals in the context of construction projects quotes an owner giving the following instruction on the format of the A3 to be submitted (Butcher 2019): "The content may be formatted and organised in whatever manner the proposer desires. The proposer may place whatever content they

\footnotetext{
${ }^{6}$ The notion of "business idea" by Normann $(1976,1977 / 1978)$ can be seen as a precursor to Business Model Canvas, although the originators of the latter do not refer to him in their key works. He distinguishes three main components of a business idea, namely the product system, niche or market segment, and the internal organization of the firm in terms of organization structure, resources and organized knowledge. A central idea is the fit, or consonance, between the different components. Normann also stresses the consonance inside each of them, among their different subcomponents. A graphical template on presenting a business idea was also developed. The concept of business idea has been widely known and also used in the Nordic countries but perhaps less elsewhere. In comparison to Business Model Canvas, the similarity of the three main components, and of the presentational mode (graphical) is striking. However, the idea of fit, consonance or integrity is much more forcefully explicated in connection to business idea than regarding Business Model Canvas.
} 
desire on the A3. This allows the proposer to use their imagination and best judgement in 'selling' their firm's experience, qualifications, capabilities, etc." This shows that the technique of A3 is only used in the sense of compressing information onto an A3 sheet the PDCA sequence has been lost.

The method of Canvas was originally carefully backed up by research (Osterwalder 2004) and thoughtfully designed to embrace the ontologically distinct entities and their relations (indicated through the positioning of the elements on the canvas). After the success of BMC, the same ideas have been adapted to many other contexts, for example, the context of project management. Indeed, a Google search reveals half a dozen proposed Project canvases, all different to each other. The assumption is that the idea of ontologically distinct entities and especially their relations has probably been lost in many cases.

\section{EXTENSIONS AND APPLICATION IN CONSTRUCTION}

In terms of the function, both methods, the A3 and Canvas, rely on the idea of establishing a common ground between the interlocutors by using a visual boundary (shared) object (Koskela et al. 2016). That is, these external representations are expected to be part of and, in a way, create a shared context for collaborators, to aid both the collaborative and individual knowledge work. Also, as both are single-page documents, these two methods aim at providing a holistic view (Gestalt) of the subject at a glance, implying the coherence of different parts of a whole.

However, A3 and Canvas were initially developed to capture different phenomena, respectively the process of problem-solving and the product of business model development. The former represents the Plan-Do-Check-Act scientific problem-solving cycle, and the latter represents the various elements of the business model and their interdependencies. It should also be noted that the different stages of an A3 also may include different product representations. For example, in the context of building design, set-based design and choosing by advantages tables may be presented on an A3 (Arroyo 2014).

As can be seen from the respective descriptions of A3 and Canvas above, these methods and techniques, especially the underlying principles of collective learning and development, as well as visualisation, have been adapted and extended into other use cases. This leads to the question, whether the same ideas and principles should and could be further adapted and extended to the context of construction and construction management. In general, considering that the 'design' (Pikas 2019) and 'making' (Ballard 2000 ), or construction production in general, are social as well as technical processes, there is a need to consider the application of these ideas. The three design principles ${ }^{7}$ provide a good starting point for developing tools for collective solving of ill-structured problems (Avdiji et al. 2018).

In addition to these principles, much can be learned from the field of codesign/participatory design, where many frameworks, process models, principles and tools for designing and developing new methods and techniques for collaborative solving of ill-structured problems have been developed (Simonsen and Robertson 2013).

\footnotetext{
${ }^{7}$ It must be noted that the idea of moving away from centralised planning and control model of management to a more inclusive approach, is a much older idea (Simonsen and Robertson 2013).
} 


\section{Practical Illustration in CONSTRUCtion}

Construction projects are essentially about the creation of new value into society, not delivered through one business but by a network of relationships between different businesses that make up the project coalition (Pryke, 2009). Within these projects, main contractors increasingly depend on their sub-contractors and suppliers, both for realising the project and for achieving the required performance (Bemelmans et al., 2012). In other words, a company's processes and activities are interrelated with the processes and activities of its surrounding companies (Broft et al., 2016) - which inevitably has direct consequences on project outcomes. In construction, these outcomes - in principle related to time, budget and quality - are generally known to be 'unsatisfying' and a good starting point for improvement. Lean construction has evolved from this need.

As mentioned above, one can already find different examples of a so-called 'Project Canvas' for the context of project management. Extending this to a construction context would mean the proposition almost automatically has to go beyond the boundary of one business or one organisation. Project team members would represent different businesses, i.e. sub-contractors and consultants. A 'Construction Project Canvas' could thus support the team members to move away from a business-focus to a focus on the entire project system respectively the whole supply chain - in line with the aim of lean construction. The central value proposition would represent the value delivered to the ultimate customer.

The Canvas method could also be used project-independently as a 'Supply Chain Management Canvas' to guide the construction supply chain in developing a successful supply chain model - what would be the value proposition of a network of organisations that have decided to establish long-term relationships? When specifically used to tackle challenges and/or improve (site) conditions, one could, i.e., talk about a 'Construction Logistics Canvas', 'Collaborative Planning Canvas' or a 'Use of Modularity and Prefabrication Canvas'.

The use of A3 has started in the construction industry - for instance, to focus a project team's conversations and to direct their decision-making process through the design phase of a project, providing a concise description of options and trade-offs associated with a problem or decision (Parrish et al. 2009). Also, A3s are known to be used in implementing target value design, where set-based-design options are discussed and studied for different criteria on an A3 report (Alves et al. 2017), or simply, to solve practical problems that occur on the 'Gemba', either on site or in the office. Extending the use of $\mathrm{A} 3 \mathrm{~s}$ in construction seems inevitable for creating an environment that is continuously improving.

\section{CONCLUSIONS}

Management science has, for a long time, been pre-occupied with decision-making. The methods of A3 and Canvas offer refreshingly new approaches addressing problemsolving and design. Their rapidly risen popularity proves that they have encountered unfulfilled needs for more effective methods and tools in management.

On the other hand, their diffusion and adaptation to new contexts are revealing a weakness: when in action, these methods are convincingly useful and start to be transmitted and learnt from peer to peer as practical tools. In this process, the underlying reasons why they work tend to get overseen - epistemological dilution occurs. In 
consequence of this, adaptations of these methods to new contexts are often less successful.

Given this situation, two research needs accentuate - a theoretical and a practical. Research should theoretically decode the underlying concepts of both A3 and Canvas so that these ideas could be presented more clearly alongside the more practical aspects of the methods. An initial set of design rules has been developed for Canvases; perhaps it would be possible to create overarching design rules covering both A3s and Canvases. In turn, applied research is needed for creating authoritative templates for specific contexts and use scenarios based on both A3 and Canvas. For example, as illustrated, it would be beneficial to have, besides a general project canvas template, a 'Construction Project Canvas' template, possibly with several versions for different construction project types, or a 'Supply Chain Management Canvas' template.

\section{REFERENCES}

Alves, T. D. C., Lichtig, W., and Rybkowski, Z. K. (2017). "Implementing target value design: tools and techniques to manage the process". HERD: Health Environments Research \& Design Journal, 10(3), pp. 18-29.

Arroyo, P. (2014). "Exploring decision-making methods for sustainable design in commercial buildings." PhD Thesis, UC Berkeley.

Avdiji, H., Elikan, D., Missonier, S., and Pigneur, Y. (2018). "Designing tools for collectively solving ill-structured problems." In: Proceedings of the 51st Hawaii International Conference on System Sciences.

Ballard, H.G. (2000). "The last planner system of production control." $\mathrm{PhD}$ Thesis, University of Birmingham.

Bemelmans, J., Voordijk, H. and Vos, B. (2012). "Supplier-contractor collaboration in the construction industry: A taxonomic approach to the literature of the 2000-2009 decade". Engineering, Construction and Architectural Management, 19(4), pp. 342368.

Broft, R.D., S. Badi and Pryke, S. (2016). "Towards SC Maturity in Construction”. Built Environment Project and Asset Management, Special Issue.

Chakravorty, S. S. (2009). "Process improvement: using Toyota's A3 reports." Quality Management Journal, 16(4), pp. 7-26.

Chanal, V. and Tannery. F. (2009). "The Role of Rhetoric in the Creation of Strategic Coherence." Symposium Communicative dimensions of strategic planning. Academy of Management, August 2009, Chicago, US. Available at https://halshs.archivesouvertes.fr/halshs-00486796/document

Clark K.B. and Fujimoto T. (1990). "The power of product integrity." Harvard Business Review, Nov-Dec; 68(6), pp. 107-118.

Dennis, P. (2007). Lean Production Simplified: A Plain-Language Guide to The World's Most Powerful Production System. Productivity Press, New York, NY.

Fujimoto, T. (1999). The Evolution of a Manufacturing System at Toyota. Oxford University Press, Oxford, UK.

Gordon, R.A. and Howell J.E. (1959). Higher Education for Business. Columbia University Press, New York.

Gregor, S., and Hevner, A. R. (2013). "Positioning and presenting design science research for maximum impact." MIS quarterly, 37(2), pp. 337-355.

Habermann, F., and Schmidt, K. (2014). The project canvas. A visual tool to jointly understand, design, and initiate projects. Availabe at: https://www.researchgate.net/ 
profile/Frank_Habermann/publication/261279649_The_Project_Canvas_-_A_Visual Tool_to_Jointly_Understand_Design_and_Initiate_Projects/links $/ 55 \mathrm{ca} 108308 \mathrm{aeb} 9$ 75674a4109.pdf.

Hevner, A., and Chatterjee, S. (2010). "Design science research in information systems." Design research in information systems, Springer, pp. 9-22.

Jackson, T. L. (2006). Hoshin Kanri for the Lean Enterprise. CRC Press, Boca Raton, FL Jimmerson, C. (2007). A3 Problem Solving for Healthcare: A Practical Method For Eliminating Waste. Productivity Press, New York, NY.

John, T., and Kundisch, D. (2015). "Why fit leads to surprise: An extension of cognitive fit theory to creative problems." Thirty Sixth International Conference on Information Systems, Fort Worth.

Jones, D., and Gregor, S. (2006). "The formulation of an information systems design theory for e-Learning." First International Conference on Design Science Research in Information Systems and Technology, Claremont, CA, pp. 356-373.

Kahneman, D. (2011). Thinking, Fast and Slow. Penguin Books.

Kalbach, J. (2016). Mapping experiences: A complete guide to creating value through journeys, blueprints, and diagrams. O'Reilly Media, Inc.

Koskela, L. (2020). "Theory of Lean Construction.” In: Tzortzopoulos, P., Kagioglou, M. and Koskela, L. (ed.). Lean Construction: Core Concepts and New Frontiers. Routledge, London, UK, pp. 2-13.

Koskela, L., Pikas, E., Gomes, D., Biotto, C., Talebi, S., Rahim, N. and Tzortzopoulos, P. (2016). "Towards Shared Understanding on Common Ground, Boundary Objects and Other Related Concepts." In: The 24th Annual Conference of the International Group for Lean Construction, 18-24 July 2016, Boston, USA, pp. 63-72.

Koskela, L., Tezel, A., \& Tzortzopoulos, P. (2018). "Why visual management." In: Proceedings of the 26th Annual Conference of the International Group for Lean Construction (IGLC), Chennai, India, pp. 250-260.

Koskela, L., Codinhoto, R., Tzortzopoulos, P., and Kagioglou, M. (2014). "The Aristotelian proto-theory of design." In: An anthology of theories and models of design. Springer, London, pp. 285-303.

Mann, D. (2017). Creating A Lean Culture: Tools to Sustain Lean Conversions. Productivity Press, Boca Raton, FL.

Maurya, A. (2010). Why Lean Canvas vs Business Model Canvas? Practice Trumps Theory. Available at: https://blog.leanstack.com/why-lean-canvas-vs-business-model -canvas-af6 2c0f250f0?gi=e0dd9750a5c5.

Normann, R. (1977). Management for growth. John Wiley \& Sons.

Normann, R. (1977/1978). "Management and Statesmanship." International Studies of Management \& Organization. 7(3/4), pp. 20-36.

Osterwalder, A. (2004). The Business Model Ontology: A Proposition In A Design Science Approach. PhD thesis, University of Lausanne, Lausanne.

Osterwalder, A., and Pigneur, Y. (2002). "An eBusiness model ontology for modeling eBusiness." BLED 2002 proceedings, 2.

Osterwalder, A., and Pigneur, Y. (2010). Business model generation: a handbook for visionaries, game changers, and challengers. John Wiley \& Sons.

Osterwalder, A., and Pigneur, Y. (2012). "Designing business models and similar strategic objects: the contribution of IS." Journal of the Association for information systems, 14(5), 237-244. 
Papert, S. (2000). "What's the big idea? Toward a pedagogy of idea power." IBM Systems Journal, 39, pp. 720-729.

Parrish, K., Tommelein, I. D., and Ballard, G. (2009). "Use of A3 reports to focus design and construction conversations." In: Proceedings of the Construction Research Congress 2009: Building a Sustainable Future, pp. 360-369.

Pikas, E. (2019). Causality and Interpretation: Integrating the Technical and Social Aspects of Design. Doctoral Dissertation, Aalto University, Espoo, Finland.

Pierson, F.C. (1959). The Education of American Businessmen, John Wiley, New York.

Pryke, S. (2009). "Construction Supply Chain Management: Concepts and Case Studies", Wiley-Blackwell, Oxford.

Raudberget, D., and Bjursell, C. (2014). "A3 reports for knowledge codification, transfer and creation in research and development organisations." International Journal of Product Development, 19(5-6), pp. 413-431.

Richardson, Y. (2011). "What are the Different Types of A3s?". Available at: https://www.lean.org/common/display/?o=1882 (Feb 18, 2020).

Sanders, E. B.-N., and Stappers, P. J. (2008). "Co-creation and the new landscapes of design." Co-design, 4(1), pp. 5-18.

Seed, B. (ed) (2010). Transforming Design and Construction: A Framework for Change. Lean Construction Institute, Arlington, VA.

Shewhart, W.A. (1931). Economic Control of Quality of Manufactured Product. D. Van Nostrand Company, New York, NY.

Shook, J. (2008). Managing to Learn: Using the A3 Management Process to Solve Problems, Gain Agreement, Mentor and Lead. Lean Enterprise Institute, Cambridge, MA.

Shook, J. (2009). “Toyota's secret”. MIT Sloan Management Review, 50(4), pp. 30-33.

Simon, H. A. (1977). "The structure of ill-structured problems." Models of discovery, Springer, pp. 304-325.

Simonsen, J., and Robertson, T. (2013). Routledge international handbook of participatory design. Routledge New York.

Sobek, D.K., and Jimmerson, C. (2006). "A3 reports: tool for organisational transformation". In: Proceedings of the 2004 Industrial Engineering Research Conference, Orlando, FL.

Sobek, D.K. \& Smalley, A. (2008). Understanding A3 Thinking. Productivity Press, Boca Raton, FL.

Suthers, D.D. (2001). "Towards a systematic study of representational guidance for collaborative learning discourse." Journal of Universal computer science, 7(3), pp. 254-277.

Tversky, B. (2015). “The cognitive design of tools of thought." Review of Philosophy and Psychology, 6(1), pp. 99-116.

Trimi, S., and Berbegal-Mirabent, J. (2012). "Business model innovation in entrepreneurship." International Entrepreneurship and Management Journal, 8(4), pp. 449-465.

Uschold, M., and King, M. (1995). Towards a methodology for building ontologies. Edinburgh: Artificial Intelligence Applications Institute, University of Edinburgh. 